\title{
Understanding the impact of slide tracheoplasty in congenital tracheal stenosis
}

\author{
Matthew S. Yong ${ }^{1,2,3}$, Igor E. Konstantinov ${ }^{1,2,3,4}$ \\ ${ }^{1}$ Department of Cardiac Surgery, Royal Children's Hospital, Melbourne, Australia; ${ }^{2}$ Department of Pediatrics, University of Melbourne, Melbourne, \\ Australia; ${ }^{3}$ Murdoch Children's Research Institute, Melbourne, Australia; ${ }^{4}$ Melbourne Children's Centre for Cardiovascular Genomics and \\ Regenerative Medicine, Melbourne, Australia \\ Correspondence to: Professor Igor E. Konstantinov, MD, PhD, FRACS. University of Melbourne; Royal Children's Hospital, Flemington Road, \\ Parkville, VIC 3029, Australia. Email: igor.konstantinov@rch.org.au. \\ Provenance: This is an invited article commissioned by the Section Editor, Xicheng Deng (Department of Cardiothoracic Surgery, Hunan Children's \\ Hospital, Changsha, China). \\ Comment on: Chen SJ, Wu ET, Wang CC, et al. Excessive Tracheal Length in Patients With Congenital Tracheal Stenosis. Ann Thorac Surg \\ 2019;108:138-45.
}

Submitted Oct 25, 2019. Accepted for publication Nov 12, 2019.

doi: $10.21037 /$ tp.2019.11.02

View this article at: http://dx.doi.org/10.21037/tp.2019.11.02

Congenital tracheal stenosis (CTS) is a rare condition that often presents in infancy with respiratory failure and requires surgical intervention. Pulmonary artery (PA) sling is commonly associated with tracheal stenosis (1). Tracheal surgery has previously been associated with a high rate of mortality and morbidity (2). Over the past 30 years, numerous surgical techniques have been proposed to correct this condition $(3,4)$. In the recent decade, slide tracheoplasty has demonstrated widespread improvement in outcomes and has emerged as the technique of choice for CTS (5-10).

This technique provides a vascularised graft with native respiratory epithelium and allows immediate tracheal stability (5). Slide tracheoplasty appears to reduce postoperative ventilation time, granulation tissue formation and mortality $(7,11)$. In large single-centre experiences, survival after slide tracheoplasty is excellent $(7,12)$. Butler et al. (12) have reported an operative mortality rate of $6 \%$ in 101 patients undergoing slide tracheoplasty. Similarly, Manning et al. (7) have reported a low operative mortality rate of $2.5 \%$ in 80 patients undergoing slide tracheoplasty. At the Royal Children's Hospital, we have reported an improvement in early outcomes since the adoption of the slide tracheoplasty technique for CTS and a multi-disciplinary approach (13). Whilst much work has been done in understanding the outcomes after tracheal surgery, little has been reported on the anatomical abnormalities of CTS and the morphological changes after slide tracheoplasty. This is a key component in better understanding the disease process and the effects of surgery.

In this context, we read with interest a recent paper by Chen et al. (14) published in the Annals of Thoracic Surgery, which provides an analysis on the morphological changes after tracheal surgery. This study is unique as it is the first to thoroughly examine these anatomical changes after slide tracheoplasty with the use of computerized tomography (CT). Between 2003 and 2018, 23 children (mean age 3.6 months) underwent slide tracheoplasty. These patients underwent CT scans before and after surgery. There was a control group comprising of 36 patients with normal airway and cardiovascular anatomy on CT scans.

The authors measured the intra-thoracic tracheal length and carinal angle from CT scans. The intra-thoracic tracheal length was divided by the length of the thorax to obtain an indexed ratio that accounted for patient size. There were two groups comprising of patients with upper $(n=2)$ and lower tracheal stenosis $(n=21)$. In the later group, the indexed trachea-thoracic ratio was approximately onethird larger than control subjects, implying a longer trachea. After surgery, the trachea-thoracic ratio became similar to control subjects. The carina angle was also wider when compared to the control subjects (121 versus 86 degrees, 
respectively). After slide tracheoplasty, this was restored close to an anatomically normal angle.

There are several limitations of the study. Due to the rarity of this condition, the sample size was small and this therefore limited a detailed statistical analysis. The CT scans did not examine the extra-thoracic portion of the trachea. Hence, the entire length of the trachea is unknown in each patient. The impact of the size of the left atrium and timing of the respiration cycle on the carina were not accounted for. Finally, the follow-up period was short with the CT scans performed at a mean of 1 year after surgery. It is unknown if there is a corresponding increase in the length and size of the trachea with somatic growth of the patient.

Nevertheless, this is an important study as it provides insight into the anatomical abnormalities associated with CTS and the changes after slide tracheoplasty. The mechanism for the longer trachea in patients with CTS affecting the lower trachea has not yet been defined. The authors speculate that there is a mismatch in the longitudinal growth of the trachea compared to the patient, hence, as the trachea elongates, the lumen narrows (14). As the trachea elongates, it may displace the primitive bronchial buds more distally, hence, widening the carinal angle (14). When performing a tracheoplasty over a long segment of CTS, the concern is excessive tension on a shortened trachea that may result in anastomotic breakdown, recurrent granulation tissue and subsequent tracheal narrowing. An interesting finding of this study (14) is that in patients with CTS, the excessive tracheal length could compensate for the reduction in tracheal length after slide tracheoplasty. Chen et al. (14) suggested that slide tracheoplasty can be performed for up to approximately two-thirds of the intrathoracic trachea, beyond this, tension relieving manoeuvres may be required. These findings provide a guide for surgeons when planning the extent of tracheal resection and reconstruction.

The normalisation of the carinal angle after slide tracheoplasty is an interesting finding. The clinical implications are unclear but the angle acuity may have impact on airflow mechanics, in particular, airflow resistance $(14,15)$. As the number of patients surviving into childhood and adulthood increases, the focus has shifted towards understanding the functional implications of tracheal surgery. A recent paper from our group examined the outcomes of PA sling and tracheal surgery in children (16). Pulmonary function testing was performed in 9 of the 11 eligible patients after tracheal surgery. The median age at pulmonary function testing was 10.4 years. All patients had been operated on during infancy. Compared to matched predicted values (based on age, gender, height), the median forced expiratory volume in one second $\left(\mathrm{FEV}_{1}\right)$ was reduced at $48 \%$, the median forced vital capacity (FVC) was reduced at $74 \%$ and the median $\mathrm{FEV}_{1} / \mathrm{FVC}$ ratio was 0.69 (16). These findings indicated a pattern of airflow obstruction. Though the patients in the study were asymptomatic, the long-term consequences remain undetermined. The observation of airflow obstruction may be due to intrinsic abnormalities of the trachea or a limitation in growth after surgery. Unfortunately, our study did not have anatomical imaging at long-term follow-up. Though Chen et al. (14) suggest that slide tracheoplasty restores tracheobronchial morphology (length and carina angle) to an anatomically normal state, these results are only limited in the shortterm and do not guarantee ongoing tracheal growth. Speggiorin et al. (17) demonstrated growth of the trachea after tracheoplasty up to 2 years after surgery. However, the long-term growth and status of the trachea as patients approach late childhood and adulthood is unknown. Hence, it is important that future large-scale multi-centre studies are conducted to assess the morphology and growth of the trachea in the long-term and to correlate it with functional testing.

\section{Acknowledgments}

Funding: MS Yong is supported by the David B. Rosenthal Scholarship (University of Melbourne), Australian Government Research Training Program Scholarship and National Health and Medical Research Council Postgraduate Scholarship (APP1133977).

\section{Footnote}

Conflicts of Interest: The authors have no conflicts of interest to declare.

Ethical Statement: The authors are accountable for all aspects of the work in ensuring that questions related to the accuracy or integrity of any part of the work are appropriately investigated and resolved.

\section{References}

1. Yong MS, d'Udekem Y, Brizard CP, et al. Surgical management of pulmonary artery sling in children. J Thorac Cardiovasc Surg 2013;145:1033-9. 
2. Andrews TM, Cotton RT, Bailey WW, et al. Tracheoplasty for congenital complete tracheal rings. Arch Otolaryngol Head Neck Surg 1994;120:1363-9.

3. Tsang V, Murday A, Gillbe C, et al. Slide tracheoplasty for congenital funnel-shaped tracheal stenosis. Ann Thorac Surg 1989;48:632-5.

4. Backer CL, Mavroudis C, Gerber ME, et al. Tracheal surgery in children: An 18-year review of four techniques. Eur J Cardiothorac Surg 2001;19:777-84.

5. Grillo HC, Wright CD, Vlahakes GJ, et al. Management of congenital tracheal stenosis by means of slide tracheoplasty or resection and reconstruction, with longterm follow-up of growth after slide tracheoplasty. J Thorac Cardiovasc Surg 2002;123:145-52.

6. Kocyildirim E, Kanani M, Roebuck D, et al. Longsegment tracheal stenosis: Slide tracheoplasty and a multidisciplinary approach improve outcomes and reduce costs. J Thorac Cardiovasc Surg 2004;128:876-82.

7. Manning PB, Rutter MJ, Lisec A, et al. One slide fits all: The versatility of slide tracheoplasty with cardiopulmonary bypass support for airway reconstruction in children. J Thorac Cardiovasc Surg 2011;141:155-61.

8. Oshima Y, Yamaguchi M, Yoshimura N, et al. Management of pulmonary artery sling associated with tracheal stenosis. Ann Thorac Surg 2008;86:1334-8.

9. Tsugawa C, Nishijima E, Muraji T, et al. Tracheoplasty for long segment congenital tracheal stenosis: Analysis of 29

Cite this article as: Yong MS, Konstantinov IE. Understanding the impact of slide tracheoplasty in congenital tracheal stenosis. Transl Pediatr 2019;8(5):462-464. doi: 10.21037/tp.2019.11.02 patients over two decades. J Pediatr Surg 2003;38:1703-6.

10. Backer CL, Russell HM, Kaushal S, et al. Pulmonary artery sling: current results with cardiopulmonary bypass. J Thorac Cardiovasc Surg 2012;143:144-51.

11. Manning PB, Rutter MJ, Border WL. Slide tracheoplasty in infants and children: Risk factors for prolonged postoperative ventilatory support. Ann Thorac Surg 2008;85:1187-91.

12. Butler CR, Speggiorin S, Rijnberg FM, et al. Outcomes of slide tracheoplasty in 101 children: a 17-year single-center experience. J Thorac Cardiovasc Surg 2014;147:1783-9.

13. Yong MS, d'Udekem Y, Robertson CF, et al. Tracheal repair in children: reduction of mortality with advent of slide tracheoplasty. ANZ J Surg 2014;84:748-54.

14. Chen SJ, Wu ET, Wang CC, et al. Excessive Tracheal Length in Patients With Congenital Tracheal Stenosis. Ann Thorac Surg 2019;108:138-45.

15. Qi S, Li Z, Yue Y, et al. Computational fluid dynamics simulation of airflow in the trachea and main bronchi for the subjects with left pulmonary artery sling. Biomed Eng Online 2014;13:85.

16. Yong MS, Zhu MZL, Bell D, et al. Long-term outcomes of surgery for pulmonary artery sling in children. Eur J Cardiothorac Surg 2019. [Epub ahead of print].

17. Speggiorin S, Gilbert TW, Broadhead M, et al. Do tracheas grow after slide tracheoplasty? Ann Thorac Surg 2012;93:1083-6. 